\title{
The virtue of nursing: the covenant of care
}

\author{
Ann Bradshaw RCN Institute, Radcliffe Infirmary, Oxford
}

\begin{abstract}
It is argued that the current confusion about the role and purpose of the British nurse is a consequence of the modern rejection and consequent fragmentation of the inherited nursing tradition. The nature of this tradition, in which nurses were inducted into the moral virtues of care, is examined and its relevance to patient welfare is demonstrated. Practical suggestions are made as to how this moral tradition might be reappropriated and reinvigorated for modern nursing. (Fournal of Medical Ethics 1999;25:477-481)
\end{abstract}

Keywords: Nursing; education; tradition; character; virtue; care; service

\section{Introduction}

There is now acknowledgement by both government $^{1}$ and opposition ${ }^{2}$ that current British nurse education has failed to produce practical carers, and may deter potential recruits. Over the last two decades, the role of the British nurse has become increasingly unclear with, on the one hand, the health care assistant and nursing auxiliary taking over what was previously thought of as "hands-on" nursing work and even more invasive procedures $^{34}$; and on the other hand, nurses expanding their role to include work done by doctors. ${ }^{5}$ Alongside this there is a review of the effectiveness of current nurse education ${ }^{6}$; a push by some for an all-graduate profession ${ }^{7}$; a crisis in recruiting and retaining nurses to work at the more basic grades ${ }^{8}$, and increasing evidence of patients being given inadequate nursing care at even basic levels. ${ }^{9} 10$

Underpinning this issue of the nature, purpose and status of British nursing is the profound change in nursing values over the preceding decades. No longer should nurses be "branded" as having a vocation ${ }^{11}$; rather nursing needs a new professional status and a new ethic to match this status. ${ }^{12}$ And it has often been argued that women should shake off economically valueless and self-denying "caring". ${ }^{13}{ }^{14}$ The values of empowerment and assertiveness have displaced the traditional nursing virtues of self-sacrificial service. As the nursing role expands, so conversely, the feeding, comforting, washing and bathing activities of care, basic to nursing, have become unattractive, mundane and menial tasks, devalued by those who seek to make the nurse into an autonomous and above all, academic, professional. The central question is whether the desire and willingness to undertake apparently menial activities involved in looking after people who are ill is sustainable without an underlying ethic of altruistic service.

\section{The lesson from history: the Nightingale tradition of nursing}

This tradition of nursing was ushered in by the early church in both the West and the East, and spread by religious orders and secular Christian philanthropy in the community. It arose from the Judaeo-Christian imperative of care for the stranger as agape, exemplified in the story of the Good Samaritan. Nightingale's revival of altruistic care, care as a covenant rather than a contract, was directly connected to the evangelical religious movements of the Victorian era. ${ }^{15-18}$

Such was the impact of this reinvigorated tradition that it affected the deeply entrenched class system of the period. At St Bartholomew's Hospital, for example, nursing probationers $1888-1890$ were daughters of architects, clergymen, farmers, manufacturers, medical men, merchants, military and naval officers, solicitors, tradesmen and stockbrokers. ${ }^{19}$ The daughter of a duke was working as an ordinary nurse in one of the wards. ${ }^{20} \mathrm{By}$ choice and inclination nurses of all classes worked with patients of all classes, cleaning, cooking, washing and dealing with bodily fluids, ingrained dirt, and infestation. Genteel and educated uppermiddle-class ladies became as servants and even paid for their training. But what made these privileged women take on such physically demanding work that was both dangerous and low in status, and with little pay?

\section{Evidence for the traditional nursing ethic}

From whatever class the woman originated she was taught to be willing to turn her hand to any work that she saw needed doing. A nursing writer in 1893 said that: "...work, that some people term 'menial', is not menial when done by her with that 'tincture' which George Herbert says, makes even 'drudgery divine'."21 The purpose of nursing was 
not occupational status, or the fulfilment of the individual nurse, it was the patient.

Because the end or purpose of nursing was clear, the aim of the apprenticeship training was to produce practitioners fit for the purpose. This was seen to involve producing nurses not only with certain skills, but most importantly, who had the right qualities and attributes: a good "character". This word was constantly used by Nightingale to her probationers. In Nightingale's view: "A woman cannot be a good and intelligent nurse without being a good and intelligent woman". ${ }^{22}$ Nursing training was ultimately a holistic, moral, educative process into which student nurses were inducted.

The nurse's primary responsibility was to the patient, the epicentre of her thinking: "The nurse must have simplicity and a single eye to the patient's good. She must make no demand upon the patient for reciprocation, for acknowledgement or even perception of her services; since the best service a nurse can give is that the patient shall scarcely be aware of any - shall perceive her presence only by perceiving that he has no wants."

Nightingale, a passionate statistician, was intensely practical. Her training was not merely the presentation of an ideal, but was concerned with real practice. The nurse's character was manifested through the tasks and procedures of care and the diligence and precision they involved. This was the carefulness of care. Nightingale described such procedures in minute detail. Seemingly unimportant and insignificant matters such as how urinals should be washed and chamber utensils should be kept were the vital details that differentiated good care from bad.

Precision, infinite carefulness, was the basis for nurse training. It was for every ward sister to show every new probationer how to do her work, not only how it should be done, but also to guard against how it should not be done. Education that would fulfil this purpose was vital. Adequate medical knowledge in subjects such as chemistry, anatomy and physiology, was to be learned from a medical instructor, and examined both orally and in writing, in order that the nurse's powers of expression to train others would thereby be developed. A good library was important. Careful jottings of doctors' comments and notes of cases were to be recorded, so that the nurse learned to observe and understand her own cases and "learn the reason of what is done" so that she would be enabled to teach others.

Although the nurse was expected to obey the physician's or surgeon's directions, this was an intelligent obedience, using discretion, realising that her obedience to the directions was conditional..$^{23}$ The key to authority, in having cord trol over others, according to Nightingale, was to have control over oneself by "the silent power of consistent life". Here there could be no pretence or dissimulation. In exercising authority nurs should not "try to 'seem' anything, but to be why्子 we would seem". ${ }^{24}$

Nursing textbooks for a century reflected the Nightingale tradition. Matrons, tutors and ware sisters constantly reiterated the same message even as their books changed through editions tô recognise scientific advances: the ethical basis of nursing arises from the moral character of the nurse and the moral ethos in which she, and late also he, was trained and worked. This was the framework on which rested technical knowledge and skills, powers of observation, attention to the intimate practical details of personal hygiene and comfort. Order, structure, diligence, supervision and method were crucial. Character formed the kindness of the nurse's manner and approach towards the patient.

The inexperienced nurse was inducted gradi্ ally into the role of care in which the wisdom an sensitivity needed to touch the human body w learned. The good nurse did not regard some tasks as menial and unworthy, to be handed down to others who were less elevated. Washing thie patient, dealing with excrement, urine, vơficis, sputum, and cleaning his or her soiled body, $\overrightarrow{\mathrm{W}}$ an essential part of care. Nurses in this Nightix gale tradition were not dealing with the manage rial, technical, spiritual or emotional only, as if this was a higher plane, they were dealing with the pe? son in his or her wholeness, including the managerial, technical, spiritual and emotional, be including also, and crucially, the base physical the diseased and often broken body. To become nurse was not just to enter into a contractual ob gation dependent on reward, it was to enter into covenant that was regardless of reciprocation.

\section{The relevance of the moral tradition of care to modern nursing}

What has been described above is a tradition nursing practice in which the good nurse was the virtuous nurse. There was a moral agreement about what the duty of the nurse involved, that if caring for the sick. But in the modern world, is MacIntyre has argued in After Virtue, ${ }^{25}$ such moral consensus has disappeared. This has affected the ethical basis of nursing. Contemporary disagreeg ment about morality, referred to by MacIntyrê, arguably underlies the current disorder andi malaise in the nursing profession. The result, Britain, is evident in a crisis and confusion abot 
the identity of the nurse, as the tradition of simple service is in fact if not in theory being abandoned. The moral principles which underpinned the nature and purpose of nursing practice have weakened and an interprofessional battle about the occupational status of nursing is occurring.

Evidence shows that the current British system is problematic in aspects of both its science and its art. ${ }^{17}{ }^{26}{ }^{27}$ It is questionable whether nurse education, because the biomedical model has been sidelined, now provides nurses with the knowledge necessary to become practically competent in modern clinical technology. It is also questionable whether nurses are prepared for basic caring. The parliamentary committee, to whom the health service ombudsman reports, was shocked to discover that some patients were left in soiled beds, without oral hygiene, unwashed and unfed. Such instances are not isolated, but are constantly repeated. ${ }^{28-30}$

\section{Core principle}

Yet, the core principle of caring for the sick, which can be argued to be rooted in the moral imperative of agape, remains critical for nursing as its primary raison d'être. While prevention of disease is important, sickness has not gone away. Neither has dying. Human beings remain susceptible to illness, vulnerability, dependence, and ultimately, death. The moral objective and imperative to care for the sick remains. The moral reasons to submit oneself to the service of people who are strangers, and who may seem at times unappreciative, unattractive, difficult and even dangerous, giving the kind of self-denying and compassionate service of washing, cleaning, holding, that being a nurse involves, still apply as they did in Nightingale's day. This is evident in modern Britain, but also internationally and interculturally.

Because this is so, the nursing community needs to rediscover an intelligible moral language with which to speak of the values and practices that caring for the sick involves. From history it can be learned that the objective of care for the sick requires certain virtues: those of diligence, patience, loyalty, respect, duty, fidelity and benevolence. Above all, the good nurse needs the virtues of compassion, dedication and selfdiscipline as well as the humility that engenders sacrificial service. Such virtues do not merely derive from attitudes, preferences or feelings, but are embodied in universal moral principles. These virtues are the dispositions which enable the person to become a good nurse - to achieve the wellbeing of those who are vulnerable - which is still the core purpose of nursing.
The common goal of nursing, as it fits into health care, needs to be reaffirmed and restored. Nurses today and in the future need to be highly trained scientists and technicians to meet increased technology in health care. The nurse must therefore be intellectually capable of learning and practising the skills needed to implement technologies. But the nurse must also be a person who is genuinely kind, compassionate and altruistic, committed to performing "menial" and basic caring tasks for the patient, ready and willing to meet the practical needs of an increasingly elderly and perhaps atomised society. It is crucial that people who are recruited into nursing are inducted into both these inseparable aspects. The balance is, and always was, fundamental to the development of the nursing service.

But current nurse education, seated in higher education, does not seem to prepare the nurse for either of these aspects. As the secretary of state for health has affirmed, nurse education needs changing: "Many nurses, when they qualify, think that they lack the practical skills necessary on a ward. The transfer of responsibility to the education sector from the health service has broken the old links between individual hospitals and nurses in training, to the disadvantage of both. Many nurses and nurse managers recognise the need for change, so I hope to carry the profession with us but reform there must be." 31 This view is supported by an opposition member, who despite her own part in nursing change, had now come to realise that nursing is ultimately a practical task. ${ }^{32}$

The reason for the current problems may be because nursing is not, and cannot be, what it has been made, an intellectual activity to be discussed and analysed; it is primarily, and at its heart, a practical activity, lived out daily in real situations with people needing help. Nursing is not articulated, it is demonstrated by its authenticity. For, as Nightingale taught, the best service a nurse can give is unspoken. The patient is not aware of being nursed, because the best nursing leaves the patient without need.

\section{Theoretical mode}

As the government and opposition now recognise, the once practical nature of nurse education has been usurped by a theoretical mode of education. Nurse education has replaced nurse training. For many, the assumption is that nursing should remain, in essence, a vocation: "After all, nursing is a vocation, is it not?". ${ }^{33}$ That this is now questionable is related to the fragmentation of the tradition. The problem with nursing is that it has become divorced from its vocational tradition, 
and the realisation has dawned that there needs now to be a reformation.

There is an alternative which builds on nursing tradition, and by recovering its purpose could revive its core values. Hospitals, as large health care institutions, could again consider providing nurse training to a recognisable standard of qualification and registration, as they have done in the past. Clinical experts, including physicians, surgeons, psychiatrists, senior clinical nurses, social workers, physiotherapists, dietitians and occupational therapists, could teach nurses. Nurses could learn in the classroom in sandwich-type courses, and on the wards and in community health centres, which might also contribute learning expertise. As with the Nightingale tradition, the objective would be practical, the learning of skill, procedure and technique, together with intellectual and technical knowledge relevant to the clinical context and patients' conditions.

Most critically, however, the emphasis should be learning how to care by developing the necessary virtues, the personal qualities of character that make a clever, knowledgeable and efficient nurse into a "good" nurse. For this to occur, however, student nurses need to learn the truth of moral precepts by example, to see them embodied in the day-to-day care of patients, so they can learn by watching what is done, and the way it is done, not merely by what is said and written. This means reviving the role of the ward sister as both teacher and ward leader, with the primary duty of care, clinical responsibility for both the wellbeing of patients and the clinical development of staff. The ward sister should be central to the observation and supervised instruction of the student in the health care team. This form of apprenticeship is intrinsic to the way of learning to be and become a nurse. In order to make this possible, clinical practice settings need to develop mechanisms of order, routine, structure, method and procedure. As they gradually learn the practicalities of nursing, by the central focus on its purpose - the patient - so student nurses will learn how to care. They will be inducted into a moral tradition, and the moral tradition would thereby be reinforced and reinvigorated. This may appeal to many nurses who come into nursing because they want to be practical carers. It is also reminiscent of the Nightingale model, a creative reappropriation of it.

\section{Conclusion}

Comforting, chatting with, holding hands with, feeding, washing, bathing, cleaning, other people when they are sick, were all traditional nursing tasks, and in many circumstances essential for patient care. ${ }^{34}$ This is no less true at the end of the twentieth century. Nightingale thought that $s \mathbb{8}$ toilsome a role could not be undertaken as just another paid job; it needed love to do it. Fo Nightingale the virtue of nursing was inextricably the covenant of care. This was its core mor function and objective, which has fragmented, and now needs to be reinvigorated. In the moder world, it would seem clear that some core mor traditions should be maintained through the professional communities that have embodied them. The moral tradition of nursing is a very good example of this truth.

Ann Bradshaw SRN, Dip N(Lond), PhD, Lecture and Clinical Fellow, RCN Institute, Radcliffe Infi⿱ mary, Oxford.

\section{References}

1 Dobson F National Health Service Parliamentary deba (Hansard). House of Commons. London: The Stationery Office, 1999; 323, 17: 36,44-45, Jan 11.

2 Bottomley V. National Health Service. Parliamentary debates (Hansard). House of Commons. London: The Statione Office, 1999; 323, 17: 44, Jan 11.

3 Thornley C. The invisible workers: an investigation into the p $\vec{\nabla}$ and employment of health care assistants in the NHS. Londog Unison Health Care, 1997

4 Thornley C. Neglected nurses, hidden work: an investigation into the pay and employment of nursing auxiliaries and assistants in $t$ NHS. London: Unison Health Care, 1998.

5 Doyal L, Dowling S, Cameron A. Challenging practice: an ation of four innovatory nursing posts in the South-West. Busto University of Bristol and The Policy Press, 1998.

6 United Kingdom Central Council for Nursing, Midwifery trod Health Visiting. Fitness for practice. London: UKCC, 1999.

7 Council of Deans and Heads of UK University Faculties fo Nursing, Midwifery and Health Visiting. Breaking the boundक ries. University of Manchester: Council of Deans and Heade, 1998.

8 House of Lords Parliamentary debates. Unstarred question $\overrightarrow{\overrightarrow{0}}$ nurses in the NHS. London: The Stationery Office, 1998; 597 168: 1539, Jun 16,

9 Health Service Commissioner for England, for Scotland an for Wales. First report for session 1997-8: annual report for 1996-97. London: The Stationery Office, 1998.

10 Meredith P, Wood C. The patient's experience of surgery: a seles tive evaluation of two hospital sites: patient satisfaction with surger audit service. London: Royal College of Surgeons, Aug 1997.

11 Brown JM, Kitson AL, McKnight TJ. Challenges in carin London: Chapman \& Hall, 1992:43.

12 Wilson-Barnett J. Ethical dilemmas in nursing. Fournal Medical Ethics 1986;12:123-6,135.

13 Salvage J. The politics of nursing. London:Heinemann, 1985 . O

14 Gilligan C. Reply to critics. In: Larabee MJ, ed. An ethic of care feminist and interdisciplinary perspectives. New York: Routledg 1993: 207-14

15 Bradshaw A. Lighting the lamp: the spiritual dimension of nursi

16 Bradshaw A. Medicine and nursing: cooperation or conflic?? British Medical fournal 1995; 311:304-5.

17 Bradshaw A. Charting some challenges in the art and science $f$ nursing Lancet 1998; 351: 438-40.

18 Bradshaw A. Yes! There is an ethics of care: an answer for Peter Allmark. Fournal of Medical Ethics 1996;22:8-12.

19 House of Lords. Report of the select committee of the Housecof Lords on metropolitan hospitals with minutes of evidence, append and index [vol xvi]. London: HMSO, 1890:167 para 2567.

20 See reference 19: 165 para 2534.

21 Dannatt A. How to become a hospital nurse. London: The Record Press, 1893:30.

22 Nightingale F. Nurses, training of; nursing the sick. In: Quaa $\mathrm{R}$, ed. A dictionary of medicine [part II]. London: Longmang Green, and Co, 1882:1038-49.

23 Nightingale F. Florence Nightingale to her nurses. Nash R, e@ London: Macmillan and Co, 1914:11. 
24 See reference 23:12-13.

25 MacIntyre A. After virtue: a study in moral theory [2nd ed] London: Duckworth,1985.

26 Bradshaw A. Defining 'competency' in nursing [part I]: a policy review. Fournal of Clinical Nursing 1997;6:347-54.

27 Bradshaw A. Defining 'competency' in nursing [part II]: an analytical review. Fournal of Clinical Nursing 1998;7:103-11.

28 House of Commons. Report of the Health Service Ombudsman for 1996-1997: Select Committee on Public Administration (HC 352). Second report: report together with the proceedings of the committee and minutes of evidence, session 1997-1998. London: The Stationery Office, 1998.
29 Willcock K. 'The tip of the iceberg': a survey of complaints registered by community health councils concerning the care of older people in NHS hospitals. London: Help the Aged, 1997.

30 Longhurst RH. A cross-sectional study of the oral health care instruction given to nurses during their basic training British Dental fournal 1998;184:453-7

31 See reference $1: 36,44-5$

32 See reference $2: 44$

33 See reference 8: 1539.

34 Gillon R. Nursing ethics and medical ethics [editorial]. fournal of Medical Ethics 1986;12:115-16, 122.

\section{News and notes}

\section{European Master in Bioethics}

A new master's programme in bioethics, European Master in Bioethics, has been developed and is now being offered by four European universities: the University of Nijmegen, the Netherlands, the Catholic University of Leuven, Belgium, Complutense University, Madrid, Spain and the University of Padova, Italy.

It is a two-year programme with sixteen one-week courses on all issues currently relevant to bioethics.

The courses will be held in Nijmegen in March 2000, in Madrid in September 2000, in Leuven, in March 2001 and in Padova in September 2001.

The programme fee is 15,000 Euro. This includes tuition fees for two years, course material, congress facilities, excursions and four months full board accommodation during the residential months.

For more information contact one of the co-ordinators: Inez Uerz - Nijmegen - + 31 (0) 243615320 i.uerz@efg.kun.nl; Chris Gastmans - Leuven - + 32 (0) 16336951 -Chris.Gastmans@med.kuleuven.ac.be 